\title{
Live second trimester intrauterine pregnancy with invasive mole: a rare case report
}

\author{
Muskaan Chhabra*, Rekha Daver
}

Department of Obstetrics and Gynecology, Grant Govt Medical College and Sir J. J. Group of Hospitals, Mumbai, Maharashtra, India

Received: 30 January 2018

Accepted: 06 February 2018

\section{*Correspondence:}

Dr. Muskaan Chhabra,

E-mail: muskan.chh@gmail.com

Copyright: (c) the author(s), publisher and licensee Medip Academy. This is an open-access article distributed under the terms of the Creative Commons Attribution Non-Commercial License, which permits unrestricted non-commercial use, distribution, and reproduction in any medium, provided the original work is properly cited.

\begin{abstract}
Gestational trophoblastic disease or gestational trophoblastic neoplasia is a collective term used to describe hydatiform mole, invasive mole, choriocarcinoma and placental site trophoblastic tumours. Since any molar pregnancy has the potential to develop into invasive mole these patients should be carefully monitored for development of malignant disease. Here we are reporting a case of invasive molar pregnancy with a single live fetus of 17 weeks gestational age. A 24 years old woman, G3P2L2 with a history of amenorrhea since approximately 5 months presented with profuse per vaginal bleeding. Ultrasound showed presence of live fetus of approximate gestational age of 17 weeks. Along with the fetus there was also presence of cystic areas with no vascularity s/o Hydatiform mole. In view of continued bleeding and severe anemia pregnancy was terminated and fetus along with vesicular tissue was expelled. On follow up Beta hcg titers showed increasing trend over the next week. Repeat USG showed extension of molar tissue into the myometrium. In view of this she was given 3 cycles of chemotherapy and eventually was discharged. She was followed up regularly with no e/o recurrence. Presence of viable fetus along with hydatiform mole is a rare occurrence in obstetric practice. After termination of pregnancy these patients should undergo follow up ultrasound and serial beta HCG titers to detect the malignant transformation. Rising beta HCG titers and invasion of myometrium on ultrasound are the ominous features suggesting malignant transformation and should be treated accordingly.
\end{abstract}

Keywords: Beta HCG, Invasive mole, Live fetus, Myometrial invasion, Methotraxate

\section{INTRODUCTION}

Gestational trophoblastic disease is a collective term used to describe conditions which include hydatiform mole, invasive mole, choriocarcinoma and placental site trophoblastic tumours. Other conditions in this spectrum include epitheloid trophoblastic tumor and placental site nodule. ${ }^{1}$ Incidence of multiple gestations (twins) with one fetus and a coexistent mole is increasing in frequency due to increased use of ovulation inducing agents. Various studies have reported its incidence to vary from 1: 25000 to 1: 100000 pregnancies. ${ }^{2}$ The most common type of mole seen with a coexistent fetus is complete hydatiform mole and incidence of partial mole with a coexisting fetus is extremely rare (between $0.005-0.01 \%$ of pregnancies) Most of these pregnancies (coexisting fetus and hydatiform mole) either result into spontaneous abortion or they are medically terminated for various maternal complications including bleeding PV, hyperemesis, preeclampsia and thromboembolism etc. ${ }^{3}$ There are some case reports which have reported continuation of pregnancy beyond 30 weeks and delivery of healthy neonates but such cases are exceptions. ${ }^{4}$ There are studies which show that there is no increased incidence of persistent gestational trophoblastic disease or gestational trophoblastic neoplasia even if the pregnancy is allowed 
to continue hence many of the obstetricians allow the pregnancy if there are no maternal or fetal complications. $^{5}$

Author are reporting this case of invasive mole in a patient with complete hydatiform mole and coexisting fetus (CHMF) because its incidence is very rare. We successfully managed this case by termination of pregnancy followed by chemotherapy (3 cycles of methotrexate with leucovorin rescue). Patient was followed up for 1 year and there was no recurrence suggesting complete response to chemotherapy.

\section{CASE REPORT}

A 24 year unregistered G3P2L2 female with history of 5 months amenorrhea presented with history of pedal edema since 3-4 days and profuse PV bleeding since 6 hours. She had 2 living children elder daughter was 3 years and younger one was 18 months of age both of them were born vaginally by home deliveries. There was no history of any systemic illness like diabetes or hypertension. On examination the patient was found to be dyspneic with a respiratory rate of $42 / \mathrm{min}$ and pulse rate of $102 / \mathrm{min}$. Blood pressure measurements showed her to be having hypotension $(90 / 60 \mathrm{~mm}$ of hg on 2 different occasions).
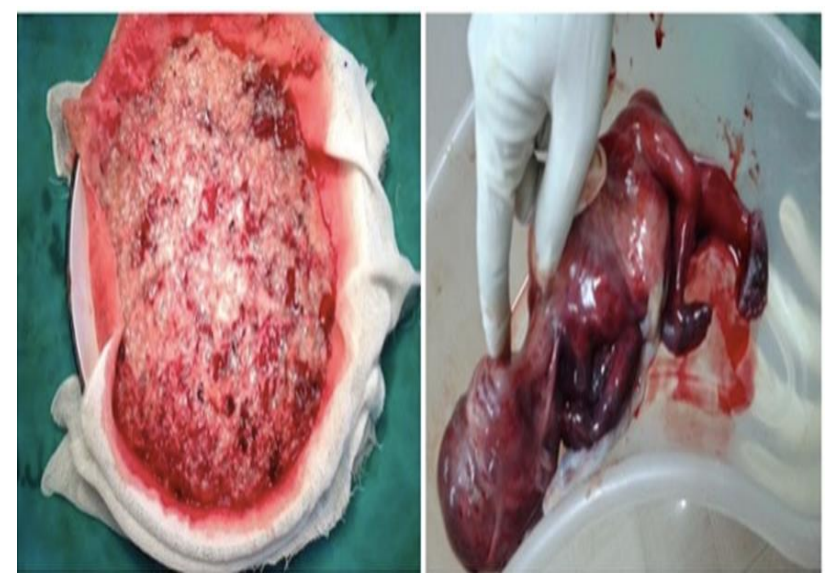

Figure 1: Expelled vesicular tissue (A) and aborted Fetus (B).

Pallor and bilateral pedal edema was present. Systemic examination was normal. Per abdominal examination revealed the height of uterus to be 36 weeks, fetal parts were not felt but fetal heart sounds could be heard well. Per speculum examination showed that the patients was bleeding profusely per vaginum with passage of clots. Per Vaginal examination showed that the os could admit tip. Since there was a history of bleeding with hypotension and presence of pallor an immediate complete blood count and blood grouping was done. $\mathrm{Hb}$ was found to be $5.7 \mathrm{gm} \%$. An ultrasound was done which showed single live intrauterine gestation of 17 weeks 15 days (effective fetal weight $206 \mathrm{gm}$ ) along with intrauterine mass lesion measuring 19.2 X 8.8 X $15.1 \mathrm{~cm}$ with multiple cystic areas suggestive of hydatiform mole. Patient was transfused with 3 units of cross matched PCV and 2 units of fresh frozen plasma. In view of continued bleeding and presence of hydatiform mole termination of pregnancy was adviced to which patient consented. Dinoprost get instillation was done and patient aborted fetus weighing 210 gms along with expulsion of 1250 gms of vesicular tissue (Figure 1).

Histopathology of aborted tissue showed features suggestive of molar pregnancy. A repeat ultrasound was done 1 week after abortion which showed nonvisualization of endometrium with loss of endomyometrial differentiation, ill-defined heterogeneous predominantly isoechoic areas and increased vascularity with low resistance on Doppler. These lesions were found to be confined to uterus and there was no extension seen into the pelvis. Both ovaries were found to be enlarged \& having multiple cysts. All these features were suggestive of Invasive mole. B-hcg titer was done which was found to be significantly elevated $(29581 \mathrm{IU} / \mathrm{ml})$. In view of ultrasound findings which suggested presence of invasive mole confined to uterus an MRI pelvis was done which showed grossly enlarged uterus with loss of endomyometrial junction and abnormal soft tissue lesions in endometrial cavity extending into myometrium of anterior and posterior wall with hemorrhage in endometrial cavity. There was no evidence of any extraserosal lesion. Both ovaries were found to be bulky with multiple cysts within. An oncology reference was done and the patient was given methotraxate (On D1, 3,5 and D7) and leucovorin rescue (On D2,4,6 and D8). Patient completed 3 cycles of chemotherapy. Weekly Bhcg levels were done till it reached the normal values $(0.5$ $\mathrm{IU} / \mathrm{ml}$ ). The patient was followed up (by B-Hcg titers) weekly for 1 month and monthly for 1 year. During last visit a repeat ultrasound and doppler examination was also done which was found to be normal suggesting a complete resolution of vesicular mole.

\section{DISCUSSION}

Twin gestations with one fetus and co-existing complete mole is a rare occurrence. The incidence has been reported to be in between $1: 25000$ to $1: 1,00,000$ pregnancies. The risk factors associated with complete molar pregnancy may include past history of molar pregnancy, past spontaneous abortion, increased maternal age and consanguinity. ${ }^{6}$ Recently increased use of ovulation induction agents like clomiphene citrate and gonadotrophins have been found to be associated with increased risk of molar pregnancy. ${ }^{7}$

In many of the cases when there is a molar pregnancy with a coexistent living fetus usually the termination of pregnancy is recommended. But in certain cases of infertility in whom the use of ovulation induction is common (risk factor for molar pregnancy) the parents may refuse the option of termination because of conception after a history of infertility. ${ }^{8}$ In women who 
wish to continue pregnancy despite the risks there is increased incidence of preterm delivery along with its associated neonatal complications like hyaline membrane disease, birth asphyxia and intracranial hemorrhage. The other fetal complications seen in these cases include intrauterine death and birth of extremely low birth weight babies. The chances of birth of a live fetus in these cases has been reported to be between $30 \%$ to $40 \%{ }^{9}$

Massardier Et al reported the incidence of gestational trophoblastic neoplasia (GTN) after complete hydatiform mole and coexisting fetus (CHMF) to be $50 \%$. Such a high incidence of GTN warrants careful management and followup of patients with CHMF. An increasing titer of B-HCG or imaging abnormalities like invasion of myometrium or extension into the pelvis on ultrasound or magnetic resonance imaging is usually indicative of GTN. Such patients need chemotherapy and close follow up for detection of recurrence. ${ }^{10}$

\section{CONCLUSION}

Though Complete Hydatiform mole and coexisting fetus (CHMF) is a rare occurrence in obstetric practice its incidence is increasing due to use of Ovulation induction agents. Even after termination of pregnancy these patients should be followed up for the probability of development of invasive mole. Rising beta HCG titers or imaging abnormalities may point towards such a possibility and these patients must receive appropriate chemotherapy.

Funding: No funding sources

Conflict of interest: None declared

Ethical approval: Note required

\section{REFERENCES}

1. Tempfer C, Horn LC, Ackermann S, Beckmann MW, Dittrich R, Einenkel J, et al. Gestational and non-gestational trophoblastic disease. guideline of the DGGG, OEGGG and SGGG (S2k Level, AWMF registry No. 032/049, december 2015). Obstet Gynecol. 2016;76(2):134.
2. Lybol C, Thomas CM, Bulten J, van Dijck JA, Sweep FC, Massuger LF. Increase in the incidence of gestational trophoblastic disease in The Netherlands. Gynecol Oncol. 2011;121(2):334-8.

3. Twiggs LB, Morrow CP, Schlaerth JB. Acute pulmonary complications of molar pregnancy. Am J Obstet Gynecol. 1979;135(2):189-94.

4. Rai 1, Shripad H, Guruvare S, Prashanth A, Mundkur A. Twin pregnancy with Hydatidiform Mole and Coexistent Live Fetus: Lessons Learnt. MJMS. 2014;21(6):61-4.

5. Vaisbuch E, Ben-Arie A, Dgani R, Perlman S, Sokolovsky N, Hagay Z. Twin pregnancy consisting of a complete hydatidiform mole and co-existent fetus: report of two cases and review of literature. Gynecol Oncol. 2005;98(1):19-23.

6. Kashanian M, Baradaran HR, Teimoori N. Risk factors for complete molar pregnancy: a study in Iran. J Reprod Med. 2009;54(10):621-4.

7. Başbuğ M, Aygen E, Tayyar M, Kaya E, Demir I, Serin S. Recurrent molar pregnancy after ovulation induction and repeat ovulation induction. A case report. J Reprod Med. 1997;42(9):600-2.

8. Tse KY, Ngan HY. Gestational trophoblastic disease. Best Pract Res Clin Obstet Gynaecol. 2012;26(3):357-70.

9. Sebire NJ, Jauniaux E. Fetal and placental malignancies: prenatal diagnose and management. Ultrasound Obstet Gynecol. 2009;33(2):235-44.

10. Massardier J, Golfier F, Journet D, Frappart L, Zalaquett M, Schott AM, et al., Twin pregnancy with complete hydatidiform mole and coexistent fetus: obstetrical and oncological outcomes in a series of 14 cases. Eur J Obstet Gynecol Reprod Biol. 2009 Apr;143(2):84-7.

Cite this article as: Chhabra M, Daver R. F Live second trimester intrauterine pregnancy with invasive mole: a rare case report. Int J Reprod Contracept Obstet Gynecol 2018;7:1657-9. 